\title{
Schisandra chinensis for dementia: a narrative overview of reviews
}

Michele Antonelli, MD; Davide Donelli, MD; Fabio Firenzuoli, MD

CERFIT, Careggi University Hospital, Florence (Italy)

\section{INTRODUCTION}

Schisandra chinensis is a plant of Chinese origin with characteristic red berries ("five flavor fruit") used for various medicinal purposes.

\section{AIM}

To understand if $S$. chinensis and its active compounds can have beneficial effects for age- and disease-related cognitive decline.

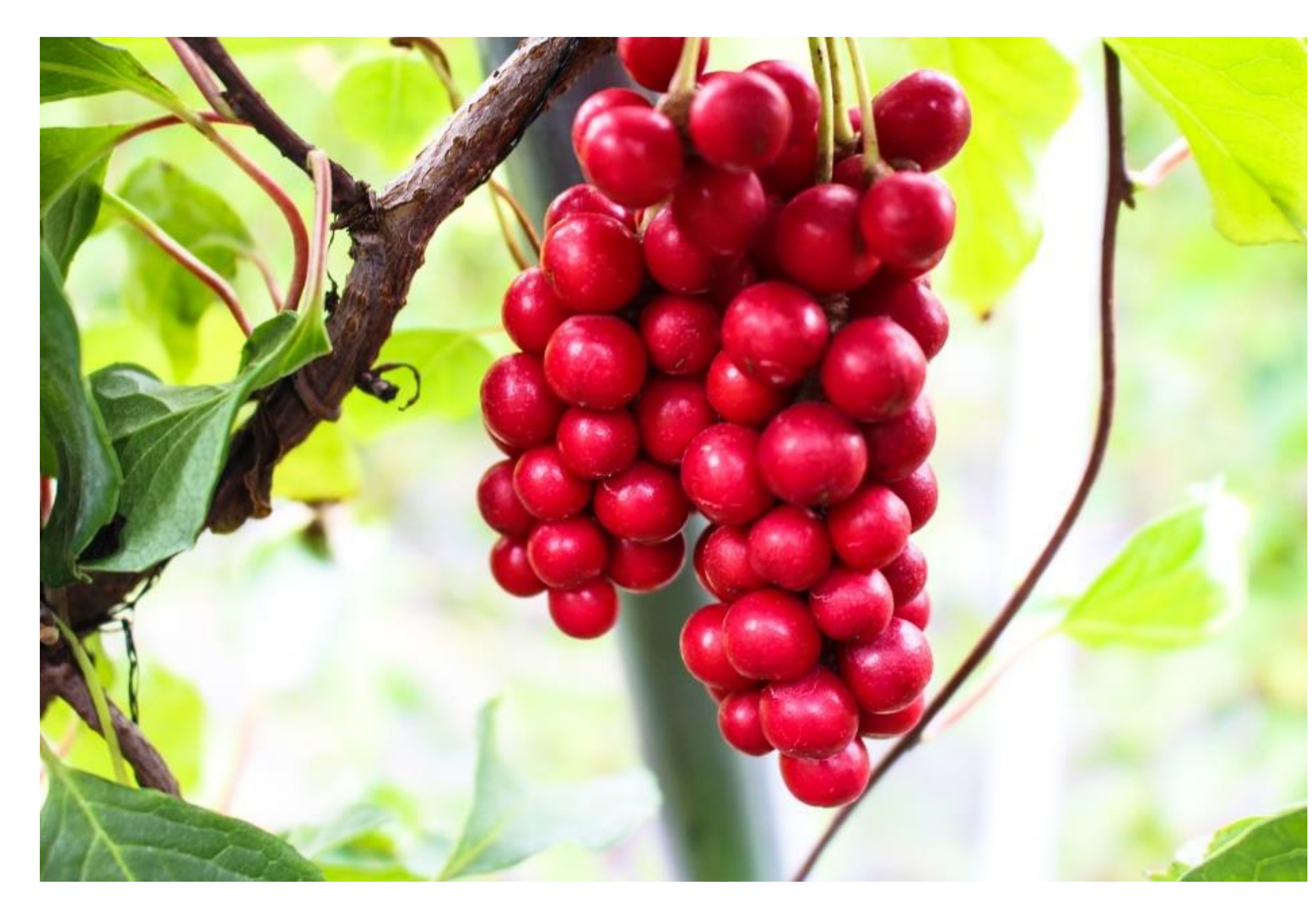

\section{METHODS}

Scientific databases: PubMed, Cochrane Library, Google Scholar.

Keywords: "Schisandra chinensis", "schisandrin", "dementia", "cognitive”, “ageing”, "brain", “Alzheimer*”. Search date: October $12^{\text {th }}, 2020$.

RESULTS
Active compounds (lignans):
Schisandrin A, schisandrin B, schisandrin C, gomisin A, schisanthenol, schisantherin A.
Study populations:
mostly mice and rat models of neuro-degeneration and brain damage.
Pharmacological effects (based on laboratory experiments):
reduction of amyloid- $\beta$-induced and glutamate-induced neurotoxicity,
decrease of neuro-inflammation (IL-1, IL-6, TNF-alpha, inducible NOS, PGE-2, COX-2),
regulation of neuronal apoptosis (calcium signaling pathway),
improvement of mood, cognitive performance and memory.
Clinical evidence (limited):
improvement of cognitive performance when S. chinensis is administered in combination with
Eleutherococcus senticosus and Rhodiola rosea.

\section{CONCLUSIONS}

Schisandra chinensis might have neuro-protective effects against some brain degenerative pathomechanisms and can be a valid option to study with dedicated clinical investigations.

\section{BIBLIOGRAPHY}

Kun, C., Feiyi, S., Jian, D., Feng, C., Guihua, W., Jiangping, Z., ... \& Xiaowei, H. (2020). Network pharmacology-based study on the mechanism of Schisandra chinensis for treating Alzheimer's disease. Indian Journal of Pharmacology, 52(2), 94.

Nowak, A., Zakłos-Szyda, M., Błasiak, J., Nowak, A., Zhang, Z., \& Zhang, B. (2019). Potential of Schisandra chinensis (Turcz.) Baill. in human health and nutrition: a review of current knowledge and therapeutic perspectives. Nutrients, 11(2), 333.

Sowndhararajan, K., Deepa, P., Kim, M., Park, S. J., \& Kim, S. (2018). An overview of neuroprotective and cognitive enhancement properties of lignans from Schisandra chinensis. Biomedicine \& Pharmacotherapy, 97, 958-968. 